\title{
PERANCANGAN APLIKASI TEKNOLOGI INFORMASI HELPDESK BERBASIS WEB PADA INSTALASI REKAM MEDIK DAN ADMISI RSCM JAKARTA
}

\author{
Arie Purwanto $^{1 *}$, Verdi Yasin ${ }^{2}$, Rachmawaty Haroen ${ }^{3}$ \\ 1,2,3 Program Studi Teknik Informatika, \\ STMIK Jayakarta \\ Sekolah Tinggi Manajemen dan Informatika \& Komputer Jayakarta \\ *e-mail: ariebonham88@gmail.com, verdiyasin29@gmail.com,rachmawatyharoen@gmail.com
}

Received: July 20, 2021, Revised: August 15, 2021 Accepted: August 20, 2021

\begin{abstract}
Abstrak
Kemajuan teknologi informasi pada zaman sekarang sangat penting dan banyak di butuhkan tidak terkecuali pada rumah sakit. Pada bagian teknisi instalasi atau admisi rekam medik, karena berpengaruh untuk jalan nya operasional rumah sakit yang mengutamakan nyawa pasien, Installasi perangkat atau masalah pada sistem atau aplikasi sering terjadi, dan oleh sebab itu untuk memperbaiki masalah tersebut secara realtime sangat di butuhkan Sebuah Sistem untuk penanganan yang di lakukan oleh IT Helpdesk yang bertujuan untuk komunikasi secara cepat, pengajuan keluhan dengan sigap pada jika ada kendala dan perbaikan pada aplikasi,. Pada aplikasi Helpdesk ini Jika User Ada keluhan atau meminta bantuan untuk intsall perangkat, kemudian yang aka di lakukan adalah input form pengajuan keluhan pada aplikasi yang akan di cek oleh teknisi. Dan apabila pengajuan yang berubpa no tiket pada aplikasi telah di respon ,maka akan segera di perbaiki jika ada yang harus di ganti atau dikomunikasi kan problem solving nya seperti apa langkah berikutnya ,dan aplikasi ini bisa di cek secara real time dan menjaga agar tidak ada keterlambatan respon terkait hal ini.
\end{abstract}

Kata kunci: Rumah sakit, Helpdesk, Admisi , Rekam Medik

\section{Abstract}

Advances in information technology today are very important and many things do not need to be done in hospitals. On the part of the installation technician or medical record admission, because it affects the operational way of the hospital that prioritizes the patient's life, installation of devices or problems in systems or applications that often occur, and therefore fixing these problems in real time is very much determined by the system for handling carried out. by the IT Helpdesk which aims to communicate quickly, submit complaints swiftly if there are problems and fix the application. In this Helpdesk application, if the user has a complaint or asks for help to install all devices, then what will be done is to submit a complaint form on the application which will be checked by a technician. And if the submission in the form of no ticket on the application has been responded to, it will be corrected immediately if something needs to be replaced or the problem solving is communicated what the next step is, and this application can be checked in real time and ensure that there are no delays response to this.

\section{Keywords: Hospital, Helpdesk, Admission, Medical Records}

\section{Pendahuluan (or Introduction)}

RSUP Nasional Dr. Cipto Mangunkusumo merupakan organisasi rumah sakit terbesar dan menjadi role model Fasilitas pelayanan kesehatan pada Sistem pelayanan kesehatan di Indonesia merasa perlu untuk selalu melakukan inovasi serta pengembangan sistem pelayanan seiring dengan peningkatan kebutuhan informasi dalam rangka penerapan Good Hospital Governance. (IRMA RSCM, 2020)

Instalasi Rekam Medis dan Admisi merupakan gabungan dari dua Unit Pelayanan yakni Unit Rekam Medis dan Unit Admisi. Penggabungan ini berdasarkan Peraturan Direktur Utama RSUP Nasional Dr. Cipto 
Mangunkusumo Nomor HK.01.07/4.2/2312/2020 Tentang Struktur Organisasi Dan Tata Kerja Instalasi Rekam Medik dan Admisi RSUP Nasional Dr. Cipto Mangunkusumo.

Pelayanan rekam medis dan admisi adalah kegiatan pelayanan penunjang secara professional yang berorientasi pada kebutuhan informasi kesehatan bagi pemberi layanan kesehatan, administrator dan manajemen pada rumah sakit berdasarkan pada ilmu rekam medis dan informasi kesehatan.

Seiring dengan berkembangnya ilmu pengetahuan dan teknologi kedokteran maka keseimbangan dalam pengelolaaan, pengintegrasian dan analisis data menjadi sumber informasi yang cepat, tepat dan akurat juga sangat dibutuhkan sehingga dapat menampilkan informasi kesehatan yang berkualitas. Oleh karena itu untuk memperluas dan mendekatkan pelayanan kesehatan kepada masyarakat yang bersifat menyeluruh, terpadu, merata dan dapat diterima dengan mutu yang baik dan biaya yang terjangkau diperlukan peningkatan kesiapan seluruh sumber daya manusia dan sumber daya lainnya serta teknologi yang tepat, efisien dan Perkembangan teknologi informasi yang sedemikian cepatnya telah membawa dunia memasuki era baru yang lebih cepat dari yang pernah dibayangkan sebelumnmya. Setidak-tidaknya ada empat era penting sejak ditemukannya komputer sebagai alat pengolah data sampai dengan era internet saat komputer menjadi senjata utama dalam berkompetensi.

Perkembangan Helpdesk diharapkan, dapat mengatasi permasalahan dan memberikan layanan terhadap seluruh permasalahan baik yang bersifat internal maupun seluruh permasalahan operasional aplikasi ataupun hal-hal yang berhubungan dengan sistem dan teknologi informasi.

Sistem Helpdesk Informasi Teknologi pada Instalasi Rekam Medik dan Admisi RSCM saat ini yang digunakan hanya menggunakan telepon, aplikasi android yaitu whatsapp dan telegram. Bila user ada suatu masalah yaitu berkaitan dengan perangkat IT, pihak user langsung menghubungi IT melalui telpon atau whatsapp. Tetapi ada keluhan dari user , apa permasalahannya sudah dikerjakan atau belum dikerjakan. Dengan adanya keluhan dari user, IT mencoba menerima keluhan ini.

Dengan adanya sistem informasi IT Helpdesk pada Instalasi Rekam Medik dan admisi RSCM. Penulis mencoba merancang Aplikasi Teknologi Informasi Helpdesk Berbasis Web. Untuk kelebihan web ini, dapat membantu user membuat formulir suatu permasalahan langsung terkirim ke IT Helpdesk Instalasi Rekam Medik dan Admisi RSCM, dapat mengontrol semua pekerjaan IT dalam suatu permasalahan langsung terkirim ke IT dalam suatu permasalahan yang berkaitan dengan perangkat informasi teknologi, dapat membantu menyusun laporan pekerjaan IT, dapat membantu pihak manajemen mengambil keputusan dengan melihat suatu masalah yang berkaitan dengan informasi teknologi, Helpdesk merupakan bantuan infomasi yang mengenai permasalahan dan troubleshooting.

Menurut Cassandra (2015-174) Helpdesk merupakan bantuan informasi yang menangani permasalahan dan troubleshooting. Fasilitas Helpdesk banyak digunakan oleh perusahaan atau instansi untuk memberikan solusi secara tepat dan memberikan kemudahan bagi pengguna atau internal perusahaan.

Berdasarkan masalah tersebut penulis mengambil skripsi yang berjudul "PERANCANGAN APLIKASI TEKNOLOGI INFORMASI HELPDESK BERBASIS WEB PADA INSTALASI REKAM MEDIK DAN ADMISI RSCM JAKARTA"

Kegunaan Sistem:

1. Mengendalikan dan mengawasi semua pekerjaan IT dalam suatu permasalahan yang berkaitan dengan perangkat Informasi Teknologi

2. Membantu menyampaikan laporan pekerjaan IT

3. Mendukung pihak manajemen mengambil keputusan dengan melihat suatu masalah yang berkaitan dengan Informasi Teknologi.

4. Membantu User mudah menghubungi IT.

\section{A. Definisi Perancangan Aplikasi}

Perancangan adalah suatu kegiatan yang memiliki tujuan untuk mendesign sistem baru yang dapat menyelesaikan masalah-masalah yang dihadapi perusahaan yang diperoleh dari pemilihan alternatif sistem yang terbaik.

Rancangan atau desain penelitian dalam arti sempit dimaknai sebagai suatu proses pengumpulan dan analisis data penelitian. Dalam arti luas rancangan penelitian meliputi proses perencanaan dan pelaksanaan penelitian. Dalam rancangan perencanaan dimulai dengan mengadakan observasi dan evaluasi terhadap penelitian yang 
sudah dikerjakan dan diketahui, sampai pada penetapan kerangka konsep dan hipotesis penelitian yang perlu pembuktian lebih lanjut.

Rancangan pelaksanaan penelitian meliputi proses membuat percobaan ataupun pengamatan serta memilih pengukuran variabel, prosedur dan teknik sampling, instrumen, pengumpulan data, analisis data yang terkumpul, dan pelaporan hasil penelitian.

Dalam pengembangannya, aplikasi dapat dikategorikan dalam tiga kelompok, diantaranya;

1. Aplikasi desktop, yaitu aplikasi yang hanya dijlankan di perangkat PC Komputer atau Laptop dengan proses instalasi

2. Aplikasi Web, yaitu aplikasi yang biasanya hanya berjalan di browser, aplikasi web bisa dibuat di local PC/Laptop atau CPanel Hosting hal ini diperlukan koneksi internet untuk mengaksesnya

3. Aplikasi Mobile, yaitu aplikasi yang dijalankan di perangkat mobile seperti Handphone atau Tablet dengan ketentuan device tersebut memiliki koneksi jaringan GSM atau seluler dan terdapat API library.

Gambar Komponen Aplikasi

\section{B. Helpdesk}

Helpdesk adalah titik pusat pelaporan masalah dan selanjutnya dikelola atau dikordinasi. Dari sudut pandang yang lebih luas, juga dilihat sebagai bagian utama dari fungsi layanan, bertanggung jawab menjembatani sumber daya untuk menyelesaikan masalah pengguna helpdesk bisa internal maupun eksternal, sehingga menjadikannya sangat penting dalam hal kelancaran organisasi dan bantuan yang kepada Helpdesk yang umum untuk pusat

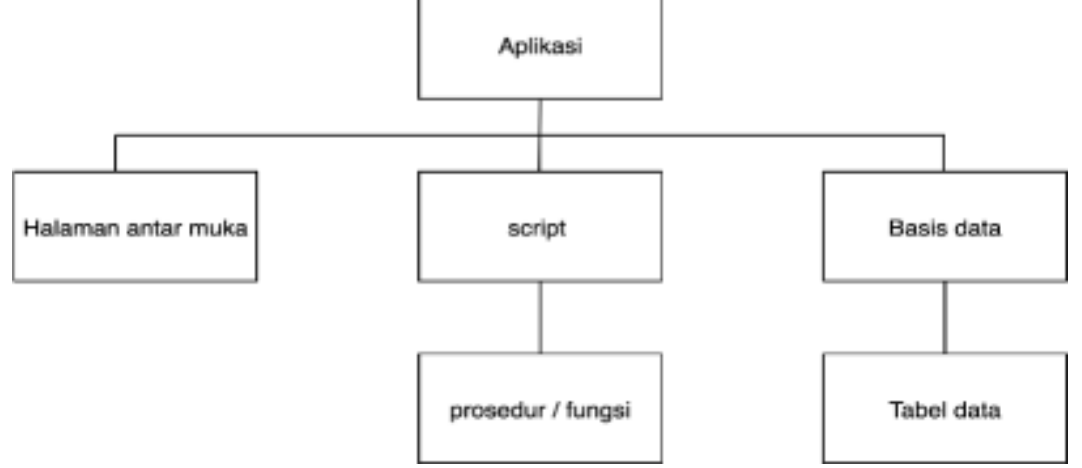
jalannya kualitas ditawarkan pelanggan. adalah nama digunakan bantuan terhadap endhelpdesk makin satu kesatuan layanan dan jawab untuk menjembatani sumber daya untuk menyelesaikan masalah dan memenuhi kepuasan user (Wibowo, 2017).

\section{Website}

Web atau lengkapnya www (world wide web) adalah sebuah koleksi dokumen-dokumen yang di simpan diinternet dan diakses menggunakan protocol (Hyper Text Transfer Protocol). Keseluruhan halaman web yang terdapat dari sebuah domain yang mengandung informasi. Sebuah website biasanya dibangun atas halaman web yang saling berhubungan. Hubungan antara banyak halaman web dengan banyak halaman web yang lainnya, antara bagian dalam halaman web yang sama disebut Hyperlink sedangkan teks yang dijadikan media

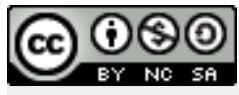


penghubung disebut Hyperteks. Sebuah website dapat diakses dalam browser, yaitu perangkat lunak untuk mengakses halaman - halaman web, seperti Internet Explorer, Mozila Firefox, Opera, Safari, Chrome dan Lainnya. Halaman website

\section{Tinjauan Literatur (or Literature Review)}

Objek penelitian merupakan hal yang paling penting dilakukan penulis, berikut deskripsi yang dilakukan oleh penulis pada objek yang dipilih oleh penulis yaitu Instalasi Rekam Medik dan Admisi RSCM Jakarta.

Instalasi Rekam Medik dan Admisi RSCM merupakan Instalasi yang bergerak dibidang Rekam Medik Pasien dan Pendaftaran Rawat Jalan maupun Rawat Inap yang beralamat JL. Diponegoro No.71, Kenari, Kec. Senen, kota Jakarta Pusat.

Berdasarkan latar belakang masalah yang telah ditemukan diatas, maka masalah dapat diidentifikasi sebagai berikut.

1. Instalasi Rekam Medik dan Admisi masih menggunakan telepon dan aplikasi whatsapp ataupun telegram

2. User menghubungi IT melalui telepon nadanya sibuk

3. User menghubungi IT melalui aplikasi whatsapp ataupun telegram lama terkirimnya.

4. Tidak adanya laporan yang lengkap dan detail

Di dalam penelitian yang dilakukan penulis dalam sistem yang sedang berjalan, penulis menemukan beberapa masalah yang terjadi pada RSCM divis Helpdesk :

a. Laporan Keluhan masih mengunakan telegram,wa dan Sms yang respon nya tergantung human itu sendiri

b. Keterlambatan waktu respon

c. Informasi dan history tidak tersimpan permanen karena bisa erjadi clear chat atau hapus perangkat

Setelah mengamati dan meneliti dari beberapa permasalahan yang terjadi pada sistem yang berjalan, penulis mngusulkan beberapa alternatif pemecahan dari permasalahan

yang dihadapi, antara lain :

1. Merancang sebuah sistem untuk Mengendalikan dan mengawasi semua pekerjaan IT dalam suatu permasalahan yang berkaitan dengan perangkat Informasi Teknologi

2.Membantu menyampaikan laporan pekerjaan IT

3. Mendukung pihak manajemen mengambil keputusan dengan melihat suatu masalah yang berkaitan dengan Informasi Teknologi.

4. Membantu User mudah menghubungi IT.

\section{$3 \quad$ Metode Penelitian (or Research Method)}

(Pada Jurnal ini penulis menggunakan sebuah metode penelitian yang sanagat banyak di gunakan karena ke efektifitasan nya sangat mudah dan teruji yaitu dengan menggunakan metode WATERFALL atau air terjun.

\subsection{SDLC Waterfall}

SDLC Waterfall sesuai namanya SDLC ini berkembang secara sistematis dari satu tahap ke tahap lain layaknya air terjun. Metode waterfall merupakan suatu metode dalam pengembangan software dimana pengerjaannya harus dilakukan secara berurutan yang dimulai dari tahap perencanaan konsep,pemodelan(design),implementasi,pengujian dan pemeliharaan.

\section{A.Tahapan Metode Waterfall}

Berikut ini merupakan tahapan tahapan pengembangan dalam metode waterfall 1.Requirement Analysis

Pada tahap ini pengembang sistem diperlukan suatu komunikasi yang bertujuan untuk memahami software yang dibutuhkan pengguna dan batasan software. Informasi ini biasanya dapat diperoleh melalui wawancara, survey atau diskusi.

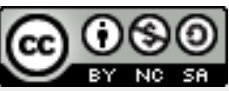




\section{System Design}

Pada proses desain, dilakukan penerjemahan syarat kebutuhan ke sebuah perancangan desain perangkat lunak yang dapat diperkirakan sebelum dibuatnya proses pengkodean (coding). Proses ini berfokus pada struktur data, arsitektur perangkat lunak, representasi interface, dan detail algoritma prosedural.

Berikut contoh desain sistem yang biasanya dibuat dan digunakan.

\section{Implementation}

Pada tahap ini terjadi proses menerjemahkan perancangan desain ke bentuk yang dapat dimengerti oleh mesin, dengan menggunakan kode kode bahasa pemrograman. Kode program yang dihasilkan masih berupa modulmodul kecil yang nantinya akan digabungkan pada tahap berikutnya.

4.Integration \& Testing

Di tahap ini dilakukan penggabungan modul-modul yang sudah dibuat dan dilakukan pengujian ini dilakukan untuk mengetahui apakah software yang dibuat telah sesuai dengan desainnya dan fungsi pada software terdapat kesalahan atau tidak.

\section{Operation \& Maintenance}

Ini merupakan tahap terakhir dalam model waterfall. Software yang sudah jadi dijalankan serta dilakukan pemeliharaan. Pemeliharaan termasuk dalam memperbaiki kesalahan yang tidak ditemukan pada langkah sebelumnya. Perbaikan implementasi unit sistem dan peningkatan jasa sistem sebagai kebutuhan baru.

\section{Waterfall}

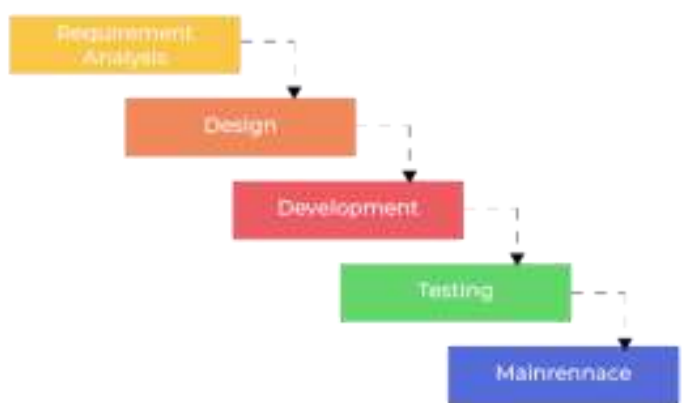

\subsection{Metode SWOT}

SWOT (strengths - weeknesses- Oportunitties- Threats )adalah metode perancangan untuk mengevaluasi kekuatan, kelemahan, peluang, dan ancaman dalam suatu proyek atau spekulasi bisnis. Analisis SWOT dapat diterapkan dalam cara menganalisis dan memilah berbagai hal yang mempengaruhi keempat faktornya kemudian menerapkannya dalam matriks SWOT, dimana aplikasinya adalah bagaimana kekuatan, mampu mengambil keuntungan dari peluang yang ada (S-O), bagaimana cara mengatasi kelemahan yang mencegah keuntungan dari peluang yang ada (W-O), selanjutnya bagaimana kekuatan mampu menghadapi ancaman yang ada (S-T), dan terakhir bagaimana cara mengatasi kelemahan yang mampu membuat ancaman menjadi nyata atau menciptakan sebuah ancaman baru (W-T) (Wikipedia:2019)

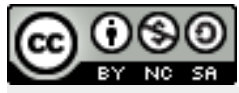


Volume 2, Nomor 2,Oktober 2021: halaman 129-145

https://jurnal.amikwidyaloka.ac.id/index.php/awl jurnal@amikwidyaloka.ac.id / editor.jurnalwidya@gmail.com

\begin{tabular}{|l|l|}
\hline \multicolumn{1}{|c|}{ ST (Strength) } & \multicolumn{1}{|c|}{ SW (Weakness) } \\
\hline $\begin{array}{l}\text { 1.Sistem terintegrasi ke IT Helpdesk } \\
\text { secara realtime Instalasi Rekam Medik } \\
\text { dan Admisi }\end{array}$ & $\begin{array}{l}\text { 1.Pelaporan keluhan hanya bisa dilakukan via } \\
\text { komunikasi Telepon, whatsapp dan Telegram. } \\
\text { 2. Kurangnya keterbukaan informasi yang } \\
\text { dapat diakses user }\end{array}$ \\
\hline $\begin{array}{l}\text { SO (Opportunity) } \\
\text { 1.Terdapat aplikasi yang dapat } \\
\text { menunjang user untuk melaporakan } \\
\text { keluhan secara langsung dan teknisi IT } \\
\text { dapat langsung menindak lanjuti } \\
\begin{array}{l}\text { 2. Data Informasi yang dapat diakses user } \\
\text { secara real time }\end{array}\end{array}$ & \begin{tabular}{l} 
keluhan secara mandiri \\
\hline
\end{tabular} \\
\hline
\end{tabular}

\section{$4 \quad$ Hasil dan Pembahasan (or Results and Analysis)}

\subsection{Usulan Prosedur Yang Baru}

Berdasarkan identifikasi permasalahan diatas, maka perumusan masalahnya adalah bagaimana membangun sebuah perancangan aplikasi IT Helpdesk berbasis web dengan menggunakan PHP, XAMPP, MYSQL, CSS, VSC, HTML, yang dinamis dan terstruktur.

\subsection{Diagram Rancangan Sistem}

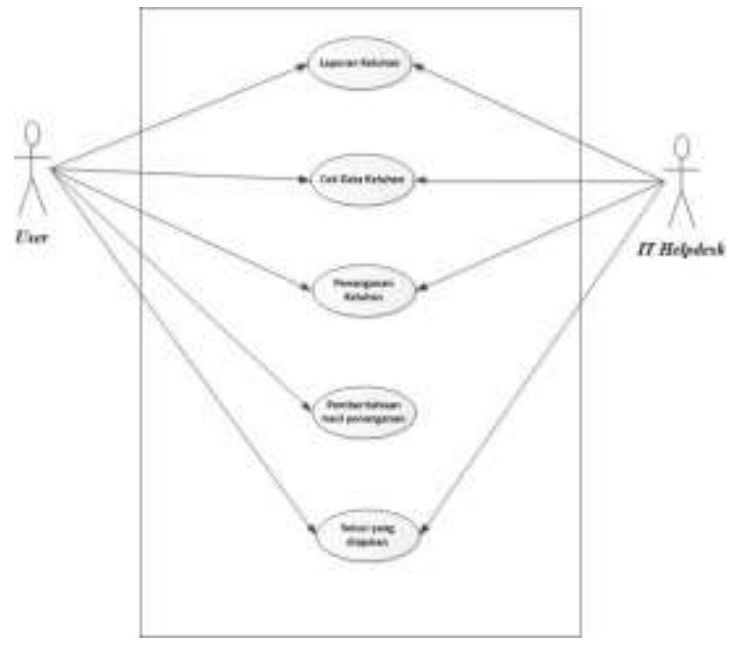

Pada usecase diatas menjelaskan pada sistem monitoring Covid ini, pengunjung hanya memiliki Akses untuk menginput form pengunjung dan juga menerima SMS pada sistem SMS Gateway, Admin memverifikasi data pengunjung dan memproses SMS gateway jika ada sa;ah satu pengujung yang terpapar covid, admin bisa merekap data pengunjung yang datang ke tempat.margin kiri; sedangkan nomor persamaan menampilkan ekspresi dengan angka Arab dalam tanda kurung harus berada di margin kanan. Letakkan garis spasi sebelum dan sesudah persamaan.

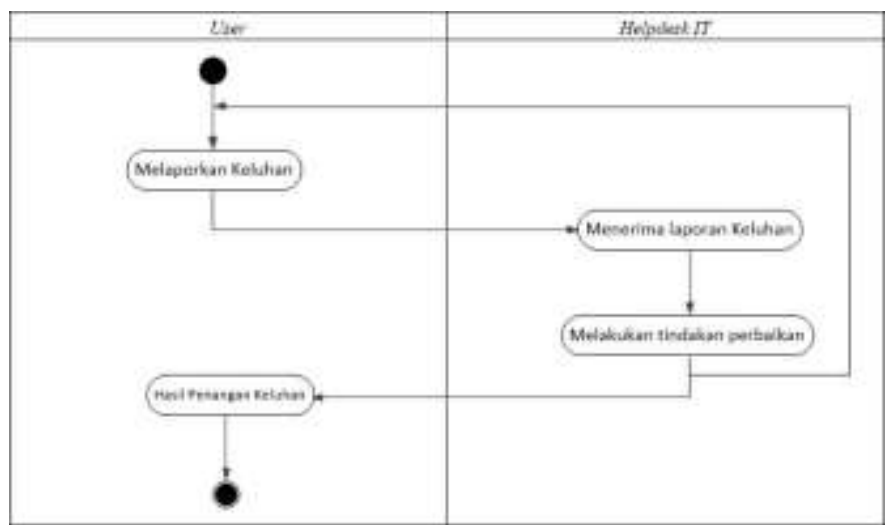

Use case diagram sistem yang berjalan menggambarkan bagaimana proses sistem IT Helpdesk yang sedang berjalan di Instalasi Rekam Medik dan Admisi 


\section{Jurnal Widya}

P-ISSN: $2746-5411$

Volume 2, Nomor 2,Oktober 2021: halaman 129-145

https://jurnal.amikwidyaloka.ac.id/index.php/awl

jurnal@amikwidyaloka.ac.id / editor.jurnalwidya@gmail.com

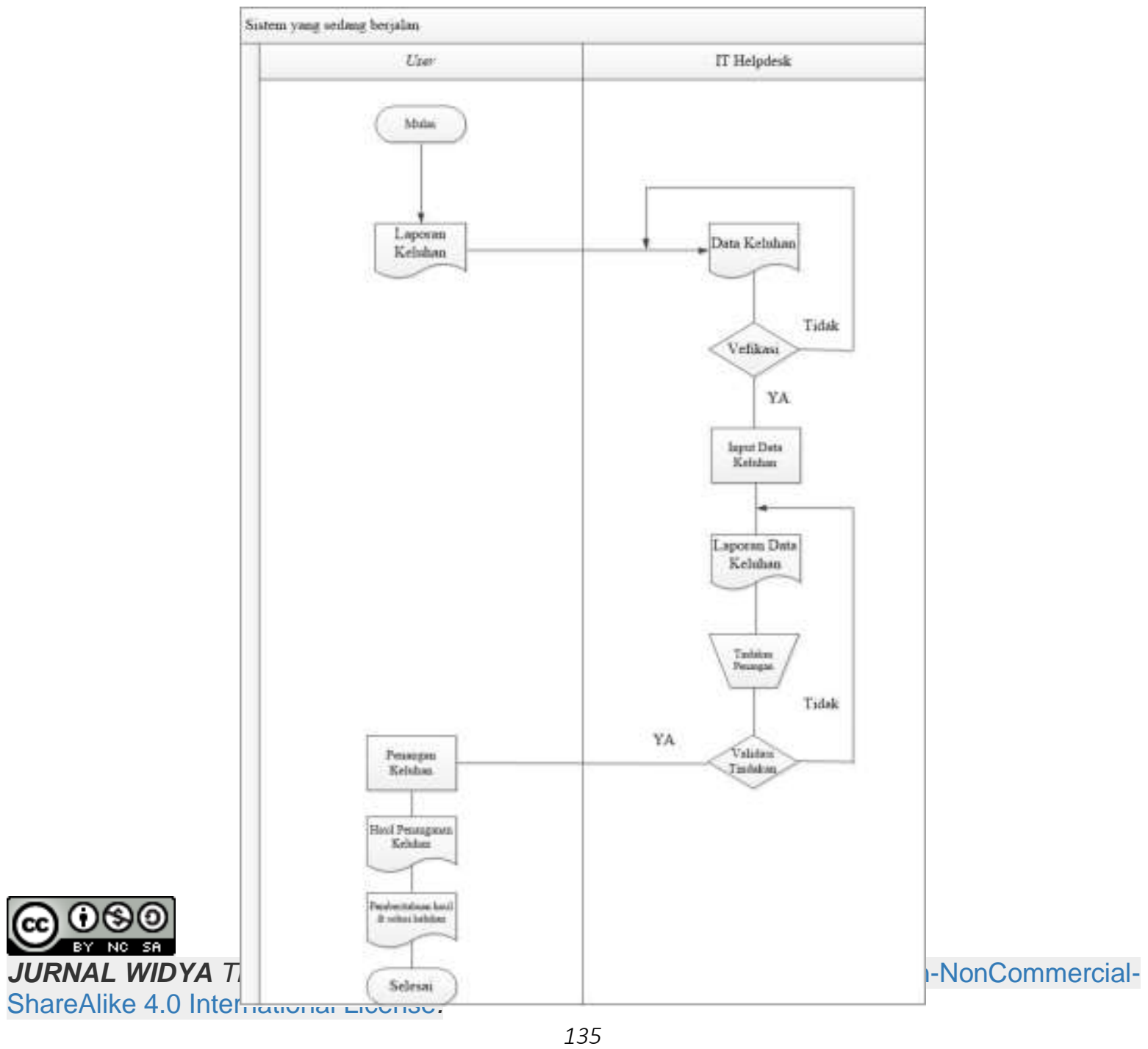




\section{Jurnal Widya}

P-ISSN: 2746-5411

Volume 2, Nomor 2,Oktober 2021: halaman 129-145

e-ISSN: 2807-5528

https://jurnal.amikwidyaloka.ac.id/index.php/awl

jurnal@amikwidyaloka.ac.id / editor.jurnalwidya@gmail.com

Gambar Flow Diagram Aplikasi 
Volume 2, Nomor 2,Oktober 2021: halaman 129-145

https://jurnal.amikwidyaloka.ac.id/index.php/awl

jurnal@amikwidyaloka.ac.id / editor.jurnalwidya@gmail.com

Gambar Usecase Sistem

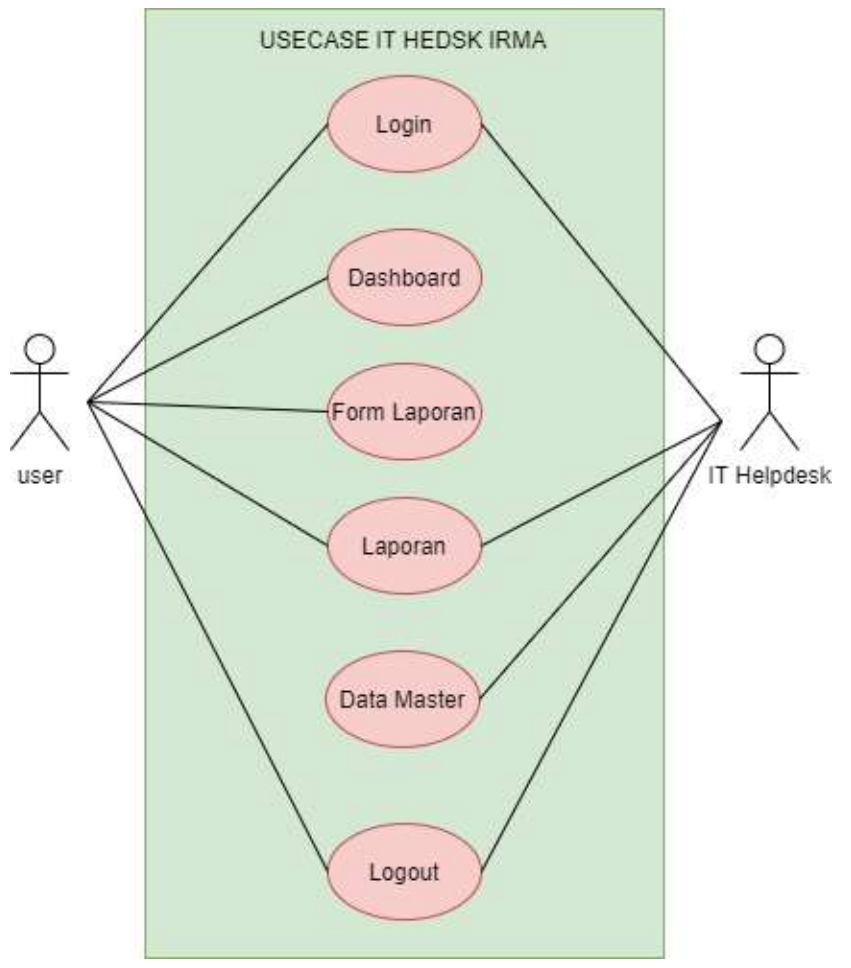

Diagram Aplikasi

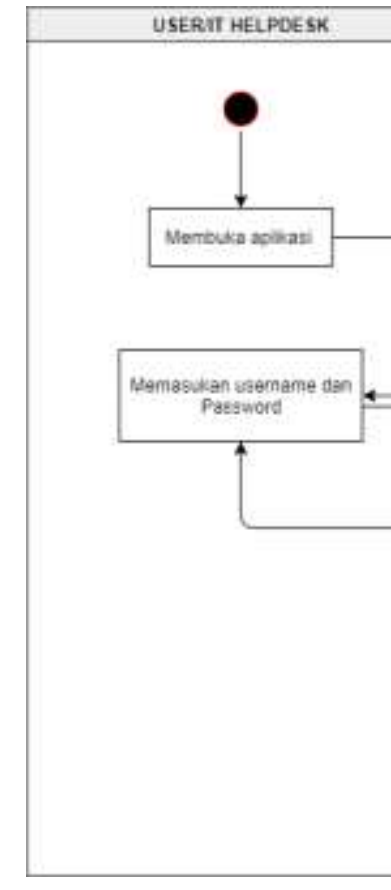

SISTEM

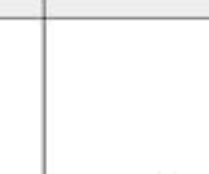

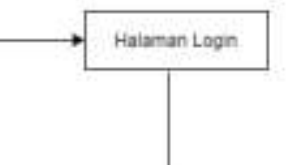

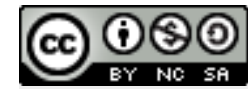

JURNAL WIDYA This We ShareAlike 4.0 Internatio
Pada Activity diagram ini User dan ITHelpdesk melakukan login, setelah itu memasukkan username dan password nya, apabila berhasil sistem akan merespon dengan menampilkan halaman Dashboard, dan apabila gagal maka sistem akan merespon kembali ke halaman login Form dan memasukan username dan password 
Volume 2, Nomor 2,Oktober 2021: halaman 129-145

https://jurnal.amikwidyaloka.ac.id/index.php/awl

jurnal@amikwidyaloka.ac.id / editor.jurnalwidya@gmail.com

Pada Activity diagram ini User menginput laporan keluhan padaa aplikasi , dengan cara membuka aplikasi, memilih menu laporan dan sub meni input laporan. Pada form laporan input jenis laporan dan deskripsi rincian laporan. Setalah menginput laporan, kemudian jika berhasil maka akan ke data laporan keluhan.

Pada Activity diagram ini keluhan yang masih open memilih data yang akan di

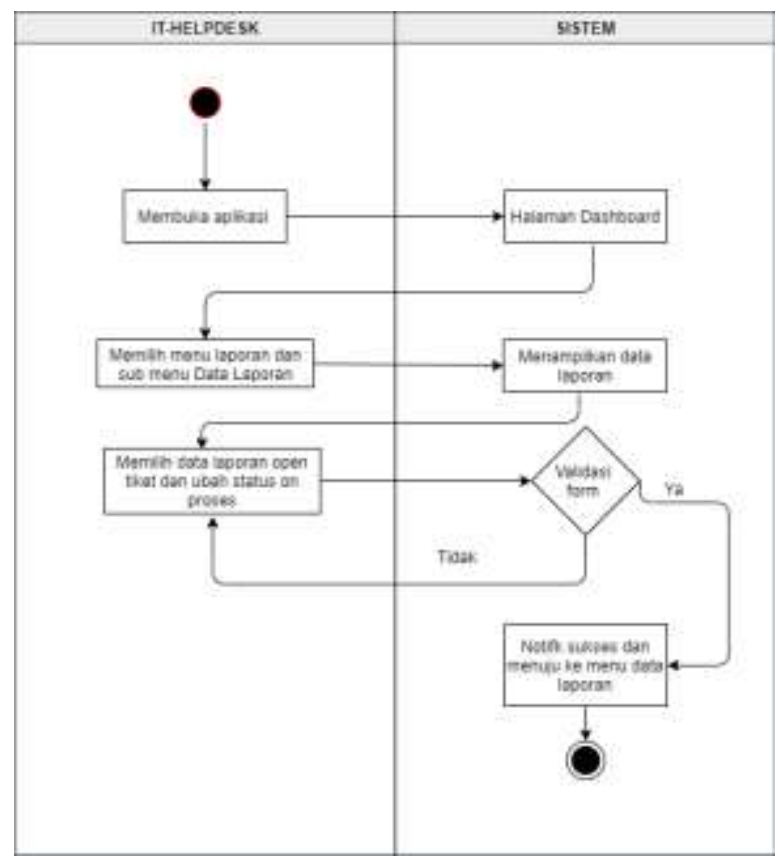

IT-Heldesk melihat dafatr tiket ataupun close, analisa da maintenance dengan mengubah status nya menjadi on proses. Ketika berhasil update akan di menuju form data laporan keluhan.

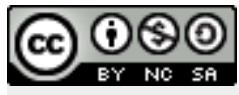

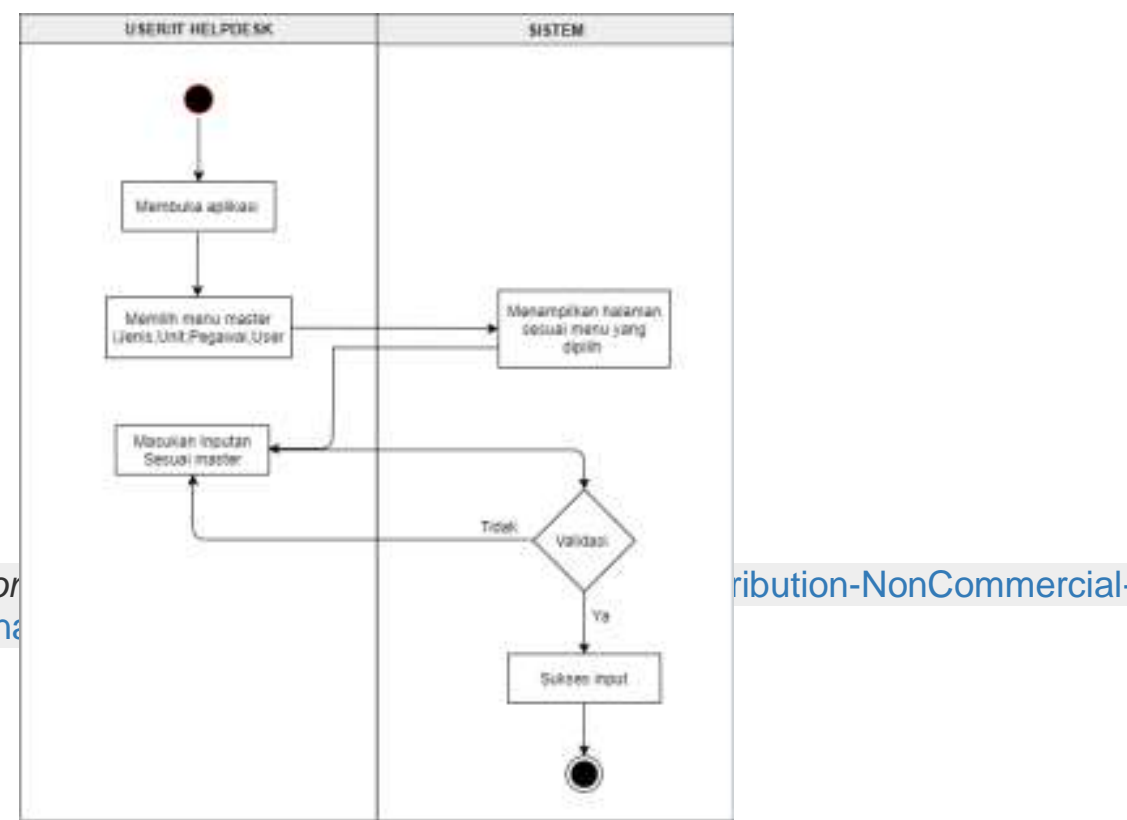


Pada Activity diagram ini User menginput laporan keluhan padaa aplikasi , dengan cara membuka aplikasi, memilih menu laporan dan sub meni input laporan. Pada form laporan input jenis laporan dan deskripsi rincian laporan. Setalah menginput laporan, kemudian jika berhasil maka akan ke data laporan keluhan.

Pada Activity diagram ini keluhan yang masih open memilih data yang akan di

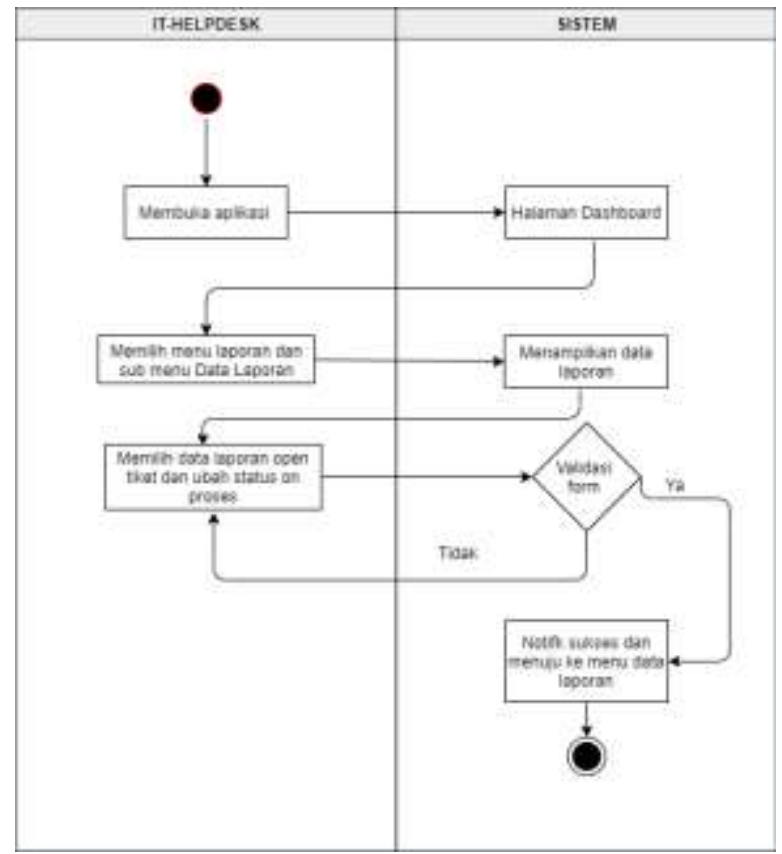

IT-Heldesk melihat dafatr tiket ataupun close, keluhan. 
Volume 2, Nomor 2,Oktober 2021: halaman 129-145

https://jurnal.amikwidyaloka.ac.id/index.php/awl

jurnal@amikwidyaloka.ac.id / editor.jurnalwidya@gmail.com

Pada Activity diagram ini IT help desk menginput kan data master sesui menu yang di pilih „, (Jenis keluhan, Unit, User dan Pegawai).

Pada Activity diagram ini melakukan logout, dengan jika berhasil logout maka form.

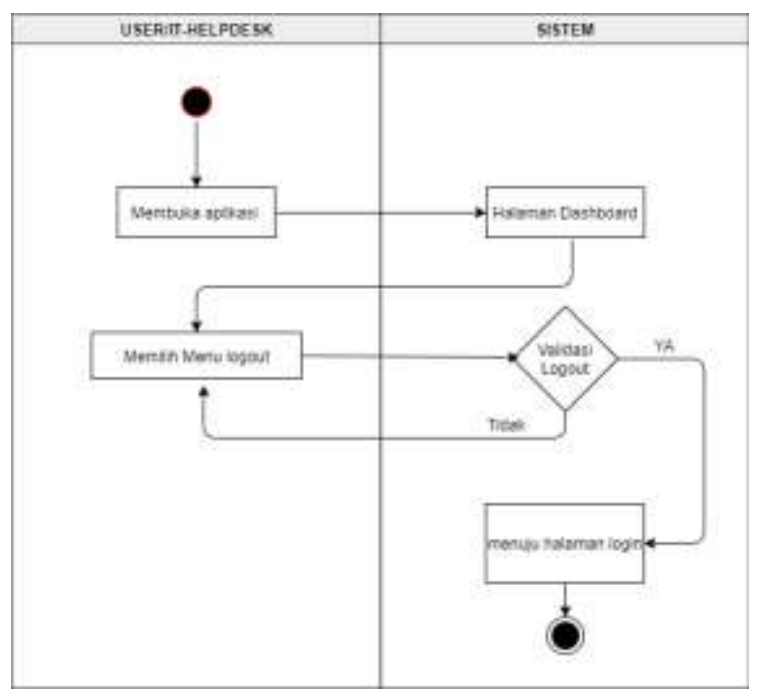

User dan IT-Helpdesk melilih menu logout, dan akan mengarah ke logoin

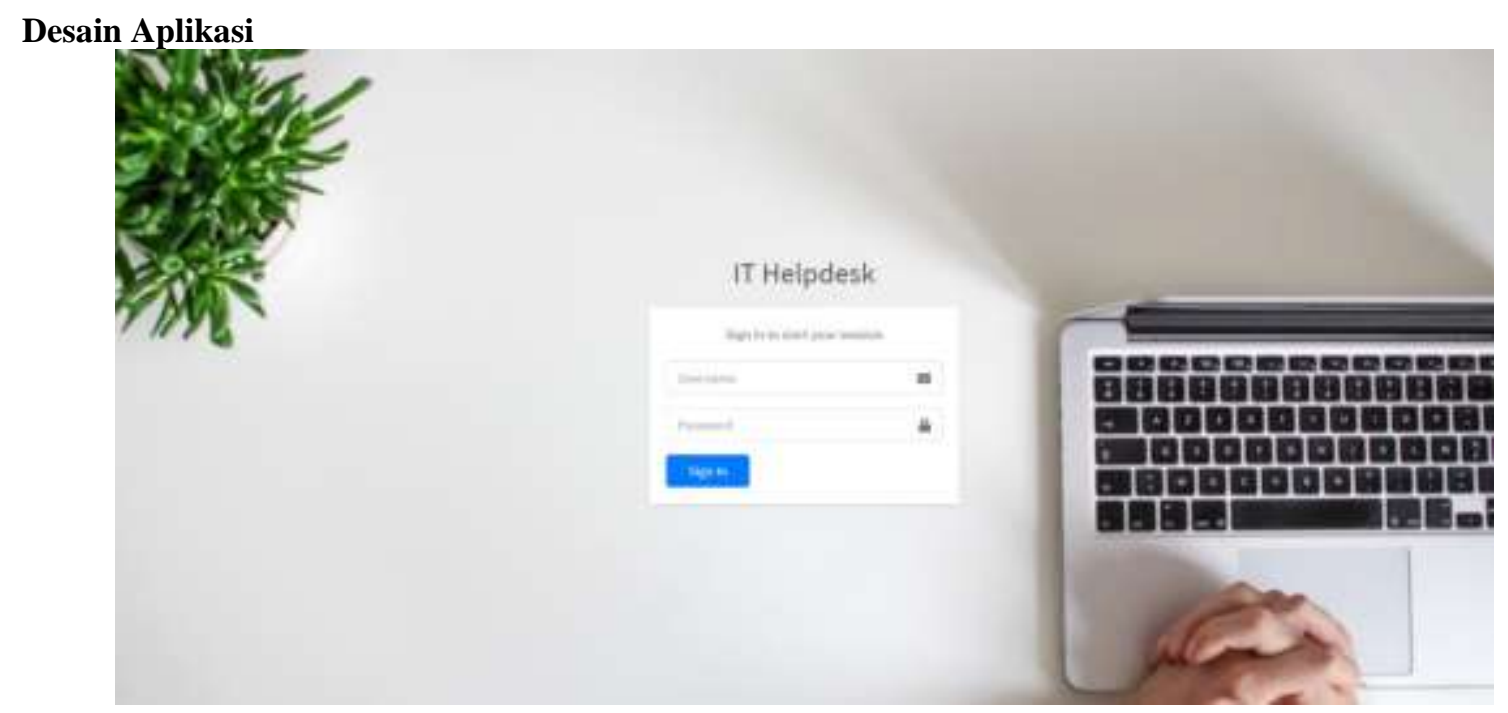

Gambar Halaman Login

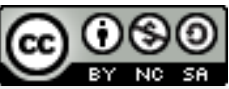

JURNAL WIDYA This work is licensed under a Creative Commons Attribution-NonCommercialShareAlike 4.0 International License. 


\section{Jurnal Widya}

P-ISSN: 2746-5411

Volume 2, Nomor 2,Oktober 2021: halaman 129-145

e-ISSN: 2807-5528

https://jurnal.amikwidyaloka.ac.id/index.php/awl

jurnal@amikwidyaloka.ac.id / editor.jurnalwidya@gmail.com

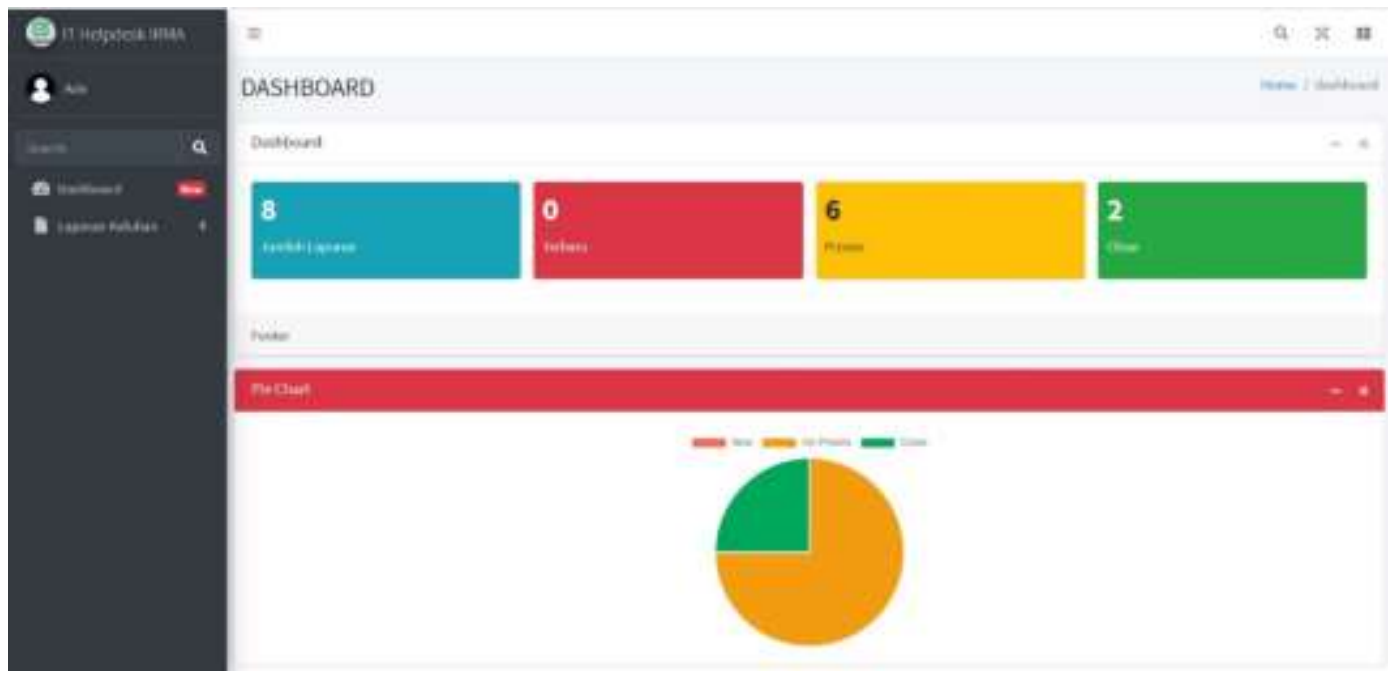

\section{Gambar Halaman Dashboard}

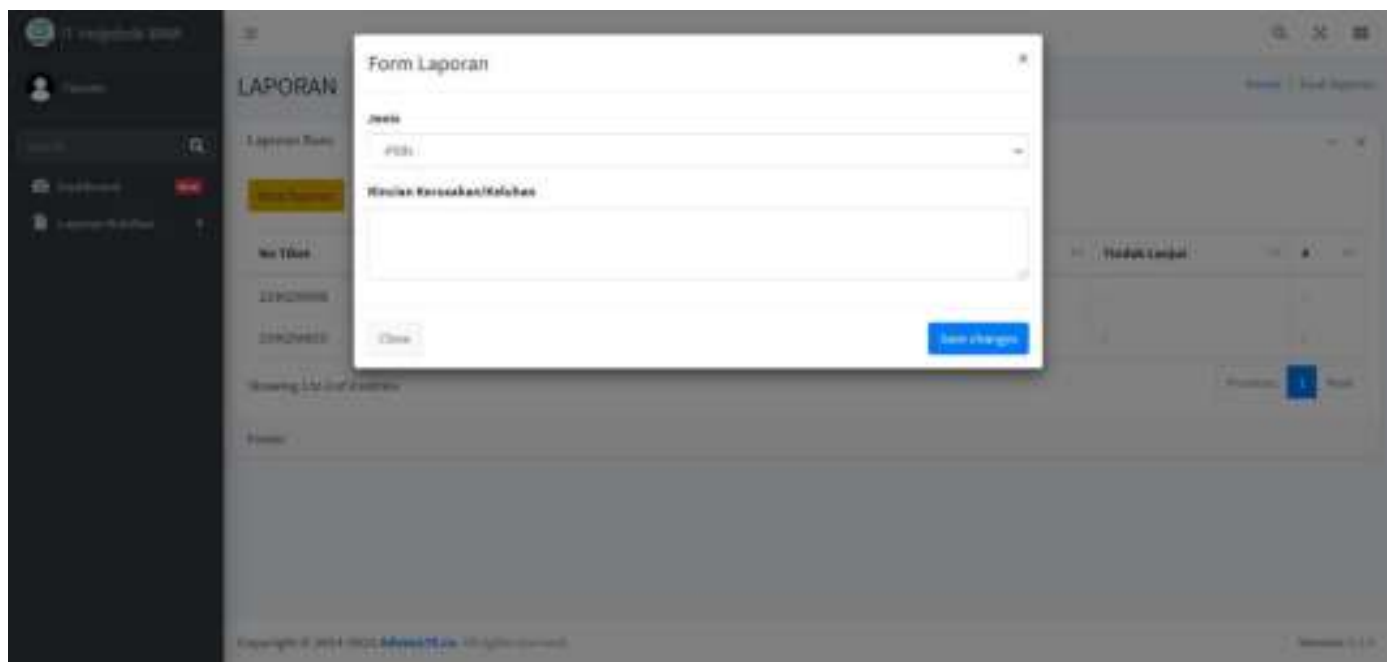

Gambar Halaman Form Input Keluhan

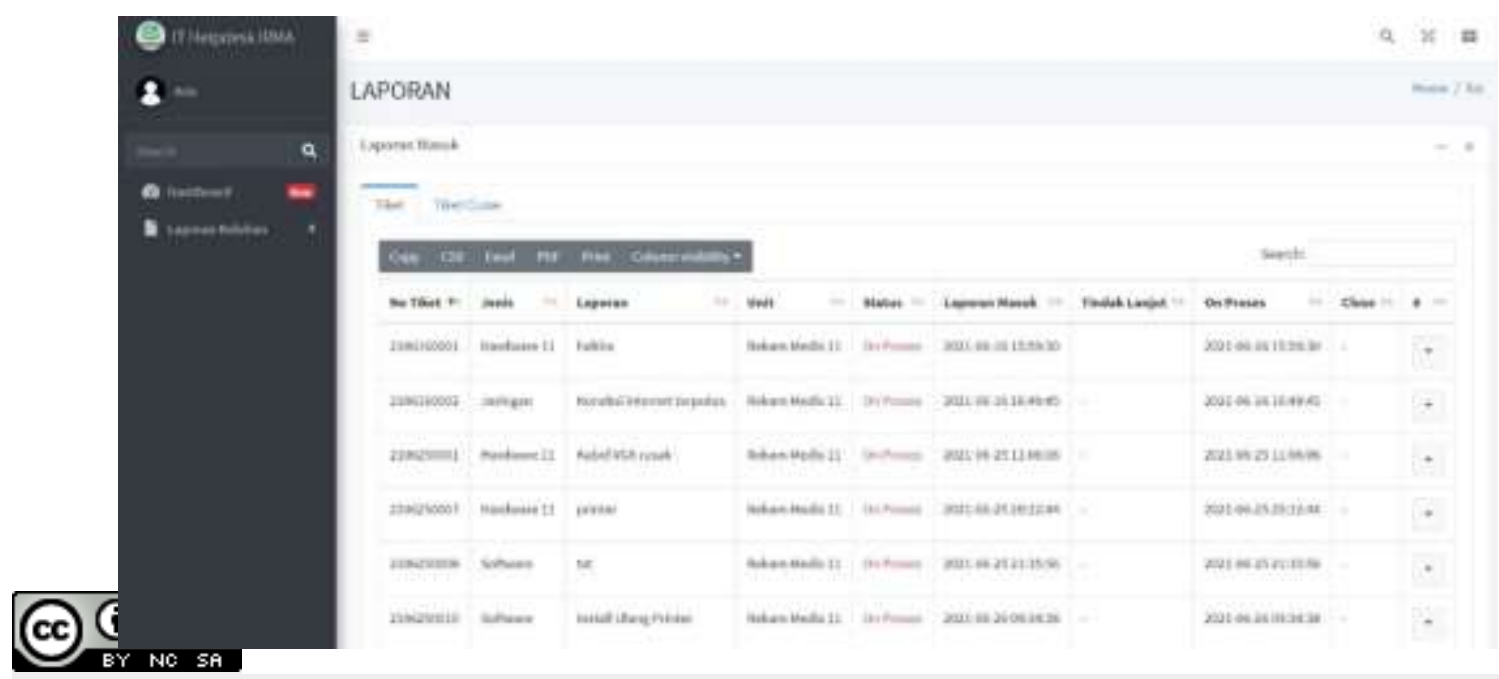

JURNAL WIDYA This work is licensed under a Creative Commons Attribution-NonCommercialShareAlike 4.0 International License. 


\section{Jurnal Widya}

P-ISSN: 2746-5411

Volume 2, Nomor 2,Oktober 2021: halaman 129-145

https://jurnal.amikwidyaloka.ac.id/index.php/awl

jurnal@amikwidyaloka.ac.id / editor.jurnalwidya@gmail.com

Gambar Halaman Data Laporan Keluhan
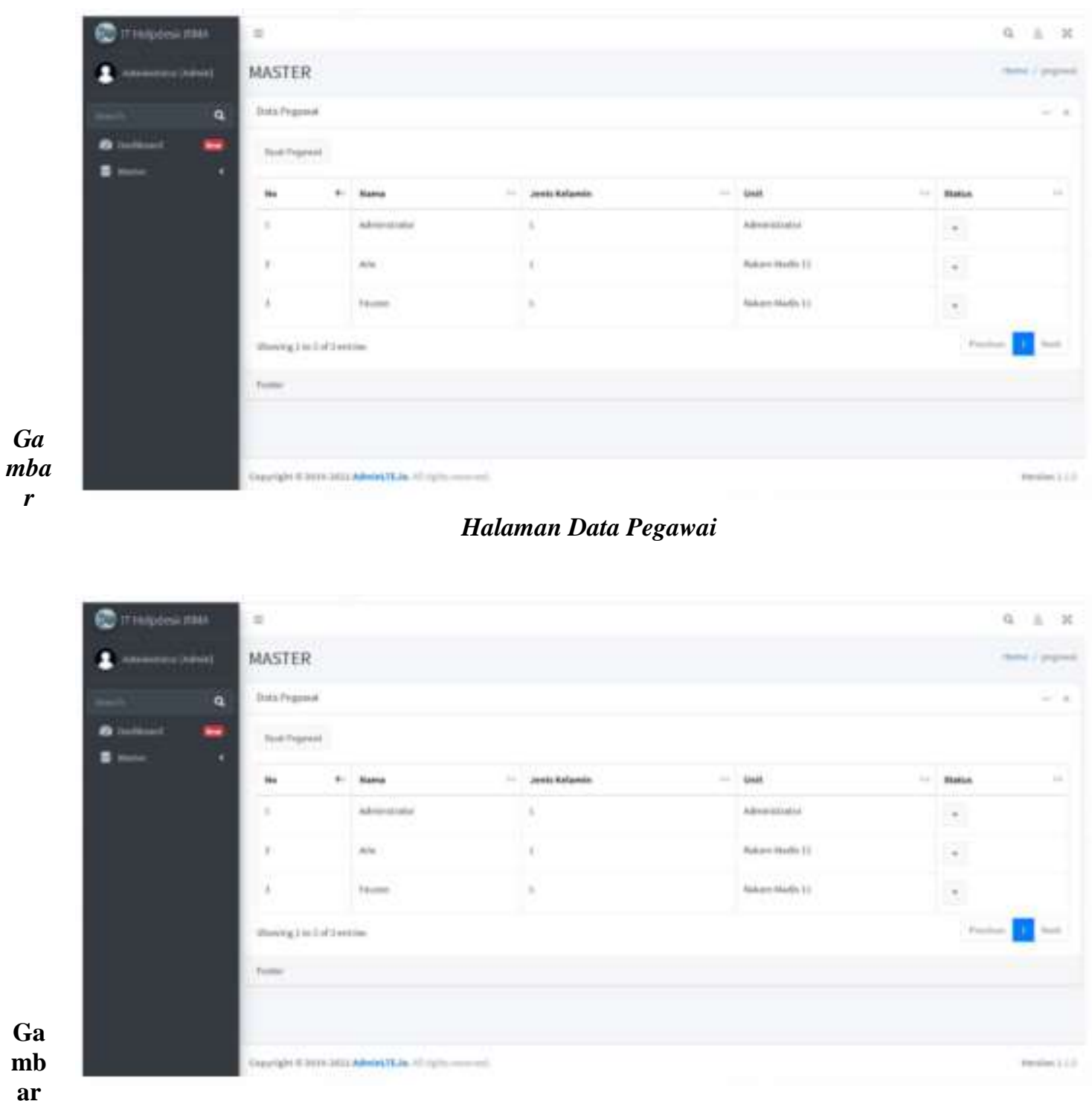

Halaman Tampilan Data User

JURNAL WIDYA This work is licensed under a Creative Commons Attribution-NonCommercialShareAlike 4.0 International License. 
https://jurnal.amikwidyaloka.ac.id/index.php/awl

jurnal@amikwidyaloka.ac.id / editor.jurnalwidya@gmail.com

\section{Kesimpulan (or Conclusion)}

\section{Kesimpulan}

Berdasarkan Hasil penelitian dan Pembahasan Sistem Pada Bab-Bab Sebelumnya, Maka dapat disimpulkan

Bahwa Perancangan Aplikasi IT-Hepdesk ini menghasilkan beberapa point penting yaitu :

1. Keluhan user bisa ter catat pada sistem

2. Data semua keluhan yang on progress dan close tercatatan pada sistem

3. Memudahkan menanggapi dengan cepat dan lebih efisien

4. Keluhan perminggu dan perbulan bisa di liat dan agar menjadi baha evaluasi kedepannya terkait divisi Helpdesk

\section{Saran}

Saran Pertama yang dapat diberikan untuk peneliti selanjutnya jika akan menggunakan penelitian ini sebagai bahan referensi yaitu dilakukan peningkatan dan pengembangan sistem dengan menambahkan fitur Chat online pada aplikasi

Saran Kedua untuk lebih lengkap dari tampilan atau versi mobile yang bisa di install di hp dan memudahkan jika ada keluhan

\section{Referensi (Reference)}

[1] Griyana, Frenti. (2013). Analisis Sistem Pengelolaan Rekam Medis Rawat Inap Rumah Sakit Umum Kota Semarang http://eprints.undip.ac.id/37027/1/Frenti_Giyana.pdf. 12 Maret 2013

[2] PORMIKI. 2015. Pentingnya Rekam Medis. PORMIKI. Jakarta

[3] Bekti, H.B. (2015). Mahir Membuat Website dengan Adobe Dreamweaver CS6, CS5 dan Jquery. Yogyakarta: C.V Andi Offse

[4] Bengkel Internet Pens-ITS, (29-Maret-2021). Modul (6) WebProgramming PHP1

[5] Dr. Kusnendi, M.S , (2020) Sistem Informasi Managemen dan Pengambilan Keputusan

[6] Indrajani. (2015). Database Design (Case Study All in One). Jakarta: PT Elex Media Komputindo.

[7] Rizky. 2009. Analisis Sistem manajemen kesehatan di RSUP Karyadi Semarang. (Jurnal). Universitas Diponegoro. Semarang. Tersedia dalam http://eprints.undip.ac.id/

[8] Wike. 2009. Kepuasan Pasien Rawat Inap Terhadap Pelayanan Perawat Di RSUD Tuguhrejo Semarang. Program Studi Magister Promosi Kesehatan Universitas Diponegoro. (Thesis). Semarang

[9] Siyoto, Sandu dan Muhammad Ali Sodik. (2015). Dasar Metodologi Penelitian. Yogyakarta: Literasi Media Publishing

[10] Stenly Ibrahim Adam, Jimmy H. Moedjahedy, Oktoverano Lengkong (2020 ) Pengembangan IT Helpdesk Ticketing Sistem Berbasis Web di Universitas Klabat, Cogito Smart Journal | VOL. 6 - NO.2, DECEMBER 2020

[11] Radita Citra Oktaviyani,. B.A.Herlambang (2019) Sistem Informasi IT Helpdesk Pada Kejaksaan Tinggi Jawa Tengah, Science And Engineering National Seminar 4 (SENS 4)- Semarang, 7 Desember 2019

[12] Ryan Muhammad Bahrudin, Mohammad Ridwan, Hardjito S Darmojo (2019) Penerapan Helpdesk Ticketing System Dalam Penanganan Keluhan Penggunaan Sistem Informasi Berbasis Web, JUTIS Vol. 7 No. 1 Bulan April 2019

[13] Abdurahman Fauz, Asep Topan Suryadi (2020).Perancangan Aplikasi IT Helpdesk Berbasis Web DI PT Panca Abadi Nan Jaya, JURNAL RESPONSIF, Vol.2 No.1 Februari 2020, pp. 99 105

[14] __ https://qwords.com/blog/pengertian-xampp/

[15] _ http://www.waskhas.com/2020/02/pengertian-use-case-diagram-dan.html

[16] _ https://experience.dropbox.com/id-id/resources/flow-state

[17] Adi Mardian, Thomas Budiman, Rachmawaty Haroen; Verdi Yasin (2021), Perancangan Aplikasi Pemantauan Kinerja Karyawan Berbasis Android di PT. Salestrade Corp. Indonesia, "Jurnal Manajemen Informatika Jayakarta", E-ISSN : 2797-0930 (Online), P-ISSN : 2746-5985 (Print), Volume 1, Nomor 3,Juli 2021, halaman 169-185, DOI: 10.52362/jmijayakarta.v1i3.481 , URL Publikasi: http://journal.stmikjayakarta.ac.id/index.php/JMIJayakarta/article/view/481 
https://jurnal.amikwidyaloka.ac.id/index.php/awl jurnal@amikwidyaloka.ac.id / editor.jurnalwidya@gmail.com

[18] Nandang Mulyana, Agus Sulistyanto, Verdi Yasin (2021), Perancangan sistem informasi pengelolaan aset it berbasis web pada pt mandiri axa general insurance, "Jurnal Manajemen Informatika Jayakarta", EISSN : 2797-0930 (Online), P-ISSN : 2746-5985 (Print), Volume 1, Nomor 3, Juli 2021, halaman 243 257, DOI: 10.52362/jmijayakarta.v1i3.498, URL Publikasi: http://journal.stmikjayakarta.ac.id/index.php/JMIJayakarta/article/view/498

[19] Maulia Usnaini, Verdi Yasin, Anton Zulkarnain Sianipar (2021), Perancangan sistem informasi inventarisasi aset berbasis web menggunakan metode waterfall, "Jurnal Manajemen Informatika Jayakarta”, E-ISSN : $2797-0930$ (Online), P-ISSN : 2746-5985 (Print) Volume 1, Nomor 1,Februari 2021, halaman 36-55, DOI: 10.52362/jmijayakarta.v1i1.415, URL Publikasi: http://journal.stmikjayakarta.ac.id/index.php/JMIJayakarta/article/view/415

[20] Putri Setiani, Ifan Junaedi, Anton Zulkarnain Sianipar, Verdi Yasin (2021), Perancangan sistem informasi pelayanan penduduk berbasis website di rw 010 Kelurahan Keagungan Kecamatan Tamansari - Jakarta Barat. "Jurnal Manajemen Informatika Jayakarta", E-ISSN : 2797-0930 (Online), P-ISSN : 27465985 (Print) Volume 1, Nomor 1,Februari 2021, halaman 20-35, DOI: 10.52362/jmijayakarta.v1i1.414, URL Publikasi: http://journal.stmikjayakarta.ac.id/index.php/JMIJayakarta/article/view/414

[21] Benni Triyono, Sri Purwanti, Verdi Yasin (2017) "Rekayasa Perangkat Lunak Sistem Informasi Pengiriman Dan Penerimaan Surat Atau Paket Berbasis Web", Journal of Information System, Applied, Management, Accounting and Research, e-ISSN: 2598-8719. p-ISSN: 2598-8700.Vol.1 No.1 (30 Desember 2017) p46-53 http://journal.stmikjayakarta.ac.id/index.php/jisamar/article/view/12

[22] Verdi Yasin, Muhammad Zarlis, Mahyuddin K.M. Nasution (2018) "Filsafat Logika Dan Ontologi Ilmu Komputer”, Journal of Information System, Applied, Management, Accounting and Research, eISSN: 2598-8719. p-ISSN: 2598-8700.Vol.2 No.2 (19 Juni 2018) p68-75 http://journal.stmikjayakarta.ac.id/index.php/jisamar/article/view/39

[23] Julinda Maya Paramudita, Verdi Yasin (2019) "Perancangan Aplikasi Sistem Penyewaan Alat Berat ", Journal of Information System, Applied, Management, Accounting and Research, e-ISSN: 25988719. p-ISSN: 2598-8700.Vol.3 No.1 (20 Februari 2019) p23-29 http://journal.stmikjayakarta.ac.id/index.php/jisamar/article/view/73

[24] Muryan Awaludin, Verdi Yasin (2020) "Application Of Oriented Fast And Rotated Brief (Orb) And Bruteforce Hamming In Library Opencv For Classification Of Plants”, Journal of Information System, Applied, Management, Accounting and Research, e-ISSN: 2598-8719. p-ISSN: 2598-8700.Vol.4 No.3 (14 Agustus 2020) p51-59 http://journal.stmikjayakarta.ac.id/index.php/jisamar/article/view/247

[25] Ifan Junaedi, Dimas Abdillah, Verdi Yasin (2020) “Analisis Perancangan Dan Pembangunan Aplikasi Business Intelligence Penerimaan Negara Bukan Pajak Kementerian Keuangan RI”, Journal of Information System, Applied, Management, Accounting and Research, e-ISSN: 2598-8719. p-ISSN: 2598-8700.Vol.4 No.3 (14 Agustus 2020) p88-101 http://journal.stmikjayakarta.ac.id/index.php/jisamar/article/view/249

[26] Verdi Yasin (2012) 'Rekayasa Perangkat Lunak Berorientasi Objek”, Penerbit: Mitra Wacana Media, Jakarta-Indonesia.

[27] Anis Rohmadi, Verdi Yasin (2020) "Desain Dan Penerapan Website Tata Kelola Percetakan Pada CV Apicdesign Kreasindo Jakarta Dengan Metode Prototyping”, Journal of Information System, Informatics and Computing._E-ISSN: 2597-3673 (Online), P-ISSN: 2579-5201 (Print) Vol. 4 No.1, June 22, 2020. Pp.70-85 http://journal.stmikjayakarta.ac.id/index.php/jisicom/article/view/210

[28] Septian Cahyadi, Verdi Yasin, Mohammad Narji, Anton Zulkarnain Sianipar (2020) "Perancangan Sistem Informasi Pengiriman Dan Penerimaan Soal Ujian Berbasis Web ( Studi Kasus: Fakultas Komputer Universitas Bung Karno)", Journal of Information System, Informatics and Computing._E-ISSN: 2597-3673 (Online), P-ISSN: 2579-5201 (Print) Vol. 4 No.1, June 22, 2020. Pp.1-16 http://journal.stmikjayakarta.ac.id/index.php/jisicom/article/view/199

[29] Ifan Junaedi, Ndaru Nuswantari, Verdi Yasin (2019) "Perancangan Dan Implementasi Algoritma C4.5 Untuk Data Mining Analisis Tingkat Risiko Kematian Neonatum Pada Bayi”, Journal of Information System, Informatics and Computing._E-ISSN: 2597-3673 (Online), P-ISSN: 2579-5201 (Print) Vol. 3 No.1, February 13, 2019. Pp.29-44. http://journal.stmikjayakarta.ac.id/index.php/jisicom/article/view/203

[30] Verdi Yasin, Anindra Ramdhan Nugraha, Muhammad Zarlis, Ifan Junaedi (2018) "Smart System Of Fast Internet Access Development Using Backbone Network Method", Journal of Information System, Informatics and Computing._E-ISSN: 2597-3673 (Online), P-ISSN: 2579-5201 (Print) Vol. 2 No. 2 , 
December 31, 2018. Pp.26-34. http://journal.stmikjayakarta.ac.id/index.php/jisicom/article/view/198

[31] Ito Riris Immasari, Verdi Yasin (2019) "Penggunaan Metode Analytic Hierarchy Process Untuk Menganalisis Faktor-Faktor Yang Mempengaruhi Pemilihan Calon Legislatif Di Dprd Ii Kota Tangerang”, Journal of Information System, Informatics and Computing. E-ISSN: 2597-3673 (Online), P-ISSN: 2579-5201 (Print) Vol. 3 No. 2, December 10, 2019. Pp.53-58. http://journal.stmikjayakarta.ac.id/index.php/jisicom/article/view/139

[32] Verdi Yasin, Muhammad Zarlis, Tulus, Erna Budhiarti Nababan, Poltak Sihombing (2019) "Rancangan Miniatur Otomatisasi Bel Listrik Pada Gerbang Pintu Menggunakan Microkontroler Atmega8535", Journal of Information System, Informatics and Computing. E-ISSN: 2597-3673 (Online), P-ISSN: 2579-5201 (Print) Vol. 3 No. 1, February 13, 2019. Pp.13-20 http://journal.stmikjayakarta.ac.id/index.php/jisicom/article/view/68

[33] Anggeri S. Nurjaman, Verdi Yasin (2020) "Konsep Desain Aplikasi Sistem Manajemen Kepegawaian Berbasis Web Pada PT. Bintang Komunikasi Utama ", Journal of Information System, Informatics and Computing. E-ISSN: 2597-3673 (Online), P-ISSN: 2579-5201 (Print) Vol. 4 No. 2, December 28, 2020. Pp.143-174_ http://journal.stmikjayakarta.ac.id/index.php/jisicom/article/view/363

[34] Verdi Yasin, Azhar Ahmad Riza, Rumadi Hartawan (2017) "Pengembangan Aplikasi Pemulihan Layanan Bencana Sistem Informasi Peneriman Negara Bukan Pajak Online Di Lingkungan Kementerian Keuangan Republik Indonesia”, Journal of Information System, Informatics and Computing. E-ISSN: $2597-$ 3673 (Online), P-ISSN: 2579-5201 (Print) Vol. 1 No. 1, September 20, 2017. Pp.33-56. http://journal.stmikjayakarta.ac.id/index.php/jisicom/article/view/4 